CLINICAL STUDY

\title{
Impaired quality of life in patients in long-term remission of Cushing's syndrome of both adrenal and pituitary origin: a remaining effect of long-standing hypercortisolism?
}

\author{
M A E M Wagenmakers ${ }^{1}$, R T Netea-Maier ${ }^{1}$, J B Prins ${ }^{2}$, T Dekkers ${ }^{1}$, M den Heijer $^{1,3}$ and A R M M Hermus ${ }^{1}$ \\ Departments of ${ }^{1}$ Endocrinology and ${ }^{2}$ Medical Psychology, Radboud University Nijmegen Medical Centre, Geert Grooteplein 10, 6525 GA Nijmegen, \\ The Netherlands and ${ }^{3}$ Department of Internal Medicine, Free University Medical Centre, De Boelelaan 1117, 1081 HV Amsterdam, The Netherlands
}

(Correspondence should be addressed to M A E M Wagenmakers who is now at Department of Endocrinology, Universitair Medisch Centrum St Radboud, Geert Grooteplein 8, route 471,6500HB Nijmegen, The Netherlands; Email: m.wagenmakers@endo.umcn.nl)

\begin{abstract}
Objective: The determinants that cause impaired quality of life (QOL) in patients in long-term remission of Cushing's syndrome (CS) are unknown. The aim of this study was to get more insight into the patient and disease characteristics related to impaired QOL in these patients.

Design: Cross-sectional study.

Methods: The QOL of 123 patients in remission of CS (age 52.2 \pm 12.0 years, 106 women, duration of remission $13.3 \pm 10.4$ years, $80 \%$ pituitary CS), assessed with seven validated questionnaires, was compared with the QOL of an age- and sex-matched control group $(n=105)$. To investigate the influence of the aetiology of CS on QOL, patients in remission of pituitary and adrenal CS were compared. Furthermore, the influence of hormonal deficiencies, treatment strategy, duration of remission, gender and age on QOL was investigated.

Results: QOL in the total patient group and each patient subgroup was significantly worse on practically all dimensions of questionnaires compared with the control group $(P<0.05)$, except for patients in remission of pituitary CS without hormonal deficiencies who had an impaired QOL on 50\% of the QOL dimensions. Subgroup analysis revealed no difference in QOL between different patient groups, especially no difference between patients in remission of adrenal and pituitary CS. Female gender and a shorter duration of remission had a negative influence on QOL in the patient group. Conclusions: QOL remains impaired in patients in long-term remission of CS regardless of aetiology, presence of hormonal deficiencies and treatment strategies. More research is needed to establish the causes.
\end{abstract}

European Journal of Endocrinology 167 687-695

\section{Introduction}

Endogenous Cushing's syndrome (CS) is associated with significant morbidity and mortality (1). Although the Cushingoid phenotype improves after curative treatment, there is accumulating evidence that not all changes in body composition, cardiovascular risk profile and cognitive function are reversible $(2,3,4)$. Furthermore, a number of studies have reported that quality of life (QOL) remains impaired in patients in long-term remission of CS $(5,6,7,8,9,10,11,12,13$, 14). However, most of these studies have major limitations (e.g. assessment of QOL was not the main purpose of the study, small numbers of patients, no control group, unvalidated questionnaires, missing data on clinical characteristics and biochemical follow-up). Furthermore, most studies have only investigated QOL in patients in remission of pituitary CS $(8,9,11,12$, 14 ), while studies that did include patients in remission of adrenal CS did not compare QOL between different patient groups $(5,10,13)$. This has made it difficult to establish patient or disease characteristics related to impaired QOL in patients in long-term remission of CS. In this respect, hypopituitarism, glucocorticoid deficiency or a persisting effect of the previous period of hypercortisolism have been suggested as possible determinants.

The aim of this study was to investigate QOL in a large group of patients in long-term remission of CS using seven validated questionnaires concerning different dimensions of QOL and to compare the QOL of the patients to a sexand age-matched healthy control group. Furthermore, to investigate the influence of the aetiology of CS on QOL, we compared the QOL of patients in remission of pituitary CS with that of patients in remission of adrenal CS. We also investigated the influence of treatment strategy and coexisting hormonal deficiencies on QOL in patients in remission of pituitary CS. 


\section{Materials and methods}

\section{Protocol}

After approval of the study by the Medical Research Ethics Committee region Arnhem-Nijmegen, all patients treated for CS from 1967 until 2007 in our hospital were identified. Medical records of all patients were retrospectively reviewed to assess data on demographics, diagnosis of CS, the aetiology of CS, the type and number of treatments that patients received and follow-up data on remission, relapses, hormonal deficiencies and mortality. Patients that were assumed to be in remission for at least 2 years, according to the medical records, were eligible for inclusion. Patients with ectopic CS, active malignancy or systemic treatment for malignancy in the past were excluded. Furthermore, all patients that were unable to answer the questionnaires (because they could not comprehend the questionnaires or the Dutch language) were excluded. All other eligible patients were asked to participate in this study. They were sent two sets of questionnaires by mail. Nonresponders received a reminder letter after 4 weeks. If they still did not respond, we attempted to contact them by telephone.

To obtain a sex- and age-matched control group, patients were asked to find their own control subject with the same age and gender among their family or friends. Written informed consent was obtained from all patients and controls before their questionnaires were enrolled in the study.

All patients underwent a $1 \mathrm{mg}$ dexamethasone suppression test after they completed the questionnaires to confirm that they were still in remission. In patients who had been treated with radiation therapy of the pituitary gland, a 24-h urinary free cortisol was measured.

The results of the questionnaires of the patient group were compared with the results of the control group. Furthermore, we compared the results of different patient subgroups. To investigate whether the aetiology of CS influences QOL, we compared patients in remission of adrenal CS with patients in remission of pituitary CS. To investigate whether the presence of hormonal deficiencies influences QOL, we compared patients in remission of pituitary CS with hormonal deficiencies with patients in remission of pituitary CS without hormonal deficiencies. We hypothesized that the hormonal deficiency that would impact QOL the most would be glucocorticoid deficiency. Therefore, we compared patients in remission of pituitary CS with hormonal deficiencies including glucocorticoid deficiency with those with hormonal deficiencies without glucocorticoid deficiency. To investigate whether treatment strategy influences QOL, we compared patients in remission of pituitary CS treated with bilateral adrenalectomy (ADX) with those treated without bilateral ADX. Furthermore, the results of each patient subgroup were compared with the results of the control group.

\section{Study population}

Two hundred and thirty-six patients met the inclusion criteria. However, 38 patients were known to be deceased and nine patients were lost to follow-up. The remaining 189 patients were invited to participate in this study. One hundred and forty-nine patients (79\%) responded, of whom 127 (85\% of the patients that responded, $67 \%$ of the patients that were invited) were willing to participate. Four patients had recurrent CS and had to be excluded, leaving 123 patients (age $52.2 \pm 12.0$ years, 106 women) that were included. The duration of remission at the time of answering the questionnaires was $13.3 \pm 10.4$ (range 2-39) years.

There was no significant difference in response rate and willingness to participate between patients that were in remission of pituitary CS or adrenal CS (114 of 146 patients $(78 \%)$ in remission of pituitary CS responded, of whom $99(68 \%)$ were willing to participate, compared with 31 of 43 patients $(72 \%)$ in remission of adrenal CS, of whom 24 (56\%) were willing to participate).

One hundred and five controls (age 51.3 \pm 12.8 years, 71 women) completed the questionnaires. Sex and age did not differ significantly between the patient and control groups (Table 1).

\section{Definitions}

Remission was defined as suppression of plasma cortisol to $\leq 50 \mathrm{nmol} / \mathrm{l}$ after overnight $1 \mathrm{mg}$ dexamethasone and absence of clinical signs and symptoms of active hypercortisolism (15) or, if a patient had received pituitary radiotherapy, a 24-h urinary free cortisol value of $<240 \mathrm{nmol} / 24 \mathrm{~h}$ for men or $<150 \mathrm{nmol} / 24 \mathrm{~h}$ for women (reference range at our institution) and absence of clinical signs and symptoms of active hypercortisolism.

Hormonal deficiency was defined as deficiency of one or more hormones. Hypothyroidism was defined as the use of thyroid hormone as substitution therapy. Hypogonadism was defined as use of testosterone substitution in men and use of oestrogen in women (no difference was made between suppletion or contraceptive therapy). GH deficiency was defined as a maximal GH response $<15.3 \mathrm{mU} / \mathrm{l}$ during an insulin tolerance test (ITT) or as a maximal $\mathrm{GH}$ response of $<12.3 \mathrm{mU} / \mathrm{l}$ during an arginine/GHRH test (16). Glucocorticoid deficiency was defined as the use of glucocorticoids. In virtually all cases, glucocorticoid deficiency was confirmed by a plasma morning cortisol $<100 \mathrm{nmol} / \mathrm{l}$ or a maximal cortisol response $<550 \mathrm{nmol} / \mathrm{l}$ during an ITT (17). Hypopituitarism was defined as deficiency of one or more of the hormones that are secreted by the pituitary gland. 
Table 1 Socio-economic characteristics and co-morbidity of patients and controls.

\begin{tabular}{lllr}
\hline & Patients $(n=123)$ & Controls $(n=105)$ & $\boldsymbol{P}$ value \\
\hline Age (years) & $52.2( \pm 12.0)$ & $51.3( \pm 12.8)$ & 0.56 \\
Gender (female) & $78 \%$ & $71 \%$ & 0.25 \\
Self-reported co-morbidity & $79 \%$ & $57 \%$ & $<0.01^{\mathrm{a}}$ \\
Hypertension & $28 \%$ & $20 \%$ & 0.18 \\
Chronic back complaints & $18 \%$ & $12 \%$ & 0.25 \\
Osteoporosis/arthrosis & $13 \%$ & $10 \%$ & 0.40 \\
Psychological problems & $11 \%$ & $5 \%$ & 0.07 \\
Pulmonary disease & $11 \%$ & $12 \%$ & 0.67 \\
Recurrent sinusitis & $10 \%$ & $6 \%$ & 0.26 \\
Diabetes mellitus (type 1 or 2) & $9 \%$ & $4 \%$ & 0.12 \\
Cardiovascular disease & $6 \%$ & $7 \%$ & 0.76 \\
Number of self-reported diseases & $1.8( \pm 1.6)$ & $1.1( \pm 1.3)$ & $<0.01^{\mathrm{a}}$ \\
Active smoker & $20 \%$ & $12 \%$ & 0.15 \\
Smoked in the past & $33 \%$ & $40 \%$ & 0.29 \\
Paid work & $51 \%$ & $70 \%$ & $<0.01^{\mathrm{a}}$ \\
Self-reported inability to work & $25 \%$ & $0 \%$ & $<0.01^{\mathrm{a}}$ \\
Education level & $1.8( \pm 0.8)$ & $2.1( \pm 0.8)$ & $0.02^{\mathrm{a}}$ \\
Relationship & $75 \%$ & $89 \%$ & $0.01^{\mathrm{a}}$ \\
Number of children & $1.5( \pm 1.5)$ & $1.6( \pm 1.3)$ & 0.53 \\
\hline
\end{tabular}

Education level: 1 , low; 2 , middle; 3 , high.

${ }^{a}$ Significant difference between patients and control subjects.

\section{QOL questionnaires}

The following set of QOL questionnaires was used in this study:

RAND-36 The Dutch translation of the RAND-36 was used, which is very similar to the Short Form-36 questionnaire (18). It comprises 36 items regarding general well-being during the past 30 days. The items are formulated as statements or questions to assess nine health concepts: i) physical functioning, ii) social functioning, iii) role limitations because of physical health problems, iv) role limitations because of emotional problems, v) mental health, vi) vitality, vii) bodily pain, viii) general health perceptions and ix) health change in the last year. Scores are calculated for each health aspect on a 0-100 scale, in which higher scores represent a better QOL (19).

Hospital Anxiety and Depression Scale The Hospital Anxiety and Depression Scale (HADS) consists of 14 items concerning anxiety and depression, measured on a four-point scale $(20,21)$. Scores range from 0 to 21 for the anxiety and depression subscales and from 0 to 42 for the total score. Higher scores indicate more anxiety or more depressive symptoms.

Checklist Individual Strength Questionnaire The Checklist Individual Strength Questionnaire (CIS) is designed to measure several aspects of fatigue (22). It consists of four dimensions: i) the subjective experience of fatigue, ii) reduction in motivation, iii) reduction in activity and iv) reduction in concentration. The questionnaire consists of 20 statements, scored on a seven-point Likert scale. The statements refer to aspects of fatigue experienced during the last 2 weeks. Scores range from 20 to 140 points. Higher scores indicate a higher degree of fatigue.

Cognitive Failures Questionnaire The Cognitive Failures Questionnaire (CFQ) detects everyday mistakes and problems regarding perception, memory, motor function and orientation (23). The first part of the questionnaire consists of 25 items and the second part indicates the influence of these items on daily life. Scores range from 0 to 100 , in which a higher score indicates more severe problems.

Appearance Self-Esteem The Appearance Self-Esteem (ASE) is a section of the Self-report State Self-Esteem Scale and comprises satisfaction with one's appearance (24). Separate use of the ASE has been reported before (25). The questionnaire consists of six statements, scored on a five-point Likert scale. Scores range from 6 to 30. A higher score indicates more self-esteem concerning a person's own appearance.

Cushing's QOL (CushingQOL) This unidimensional questionnaire, with a time frame referring to the preceding 4 weeks, covers several Cushing-related problems. It has been designed to analyse QOL in patients with active CS (26). We used the questionnaire to analyse whether patients in long-term remission of CS still have more CS-related symptoms than healthy controls. The answers are scored on a five-point Likert scale. The total score is converted to a $0-100$ scale in which 0 indicates the worst and 100 the best possible QOL.

Nottingham Health Profile The Nottingham Health Profile (NHP) contains 38 yes/no items that focus on general well-being and current health perception $(27,28)$. The items are subdivided into six subscales 
that assess different health aspects: i) energy, ii) pain, iii) emotional reaction, iv) sleep, v) physical ability and vi) social isolation. Subscale scores are calculated as a weighted mean of the associated items and are expressed as a value between 0 and 100. A higher score is associated with a worse QOL.

Employment status and self-reported co-morbidity All participants received a questionnaire regarding their employment status. The most important aspects of this questionnaire were current employment, number of working hours per week, current sick leave and inability to work. Furthermore, participants received a checklist mentioning 16 common diseases (e.g. diabetes mellitus, cardiovascular disease, hypertension and psychiatric problems). They were asked whether they currently had any of these problems. They could also describe other health problems they experienced at the moment.

\section{Statistical analysis}

Data were analysed using SPSS for Windows version 16.0 (SPSS, Inc., Chicago, IL, USA). Data were expressed as mean \pm s.D., unless otherwise mentioned. To compare biometric and socio-economic characteristics of patients and controls, we used unpaired $t$-tests and $\chi^{2}$ tests. To compare the results of the questionnaires of patients and controls, and those of the different patient subgroups, we chose to use the Kruskal-Wallis equality-of-populations rank test because the data of several questionnaires were not normally distributed. Furthermore, using multiple regression analysis, the influence of duration of remission (between 2 and 5 years, 5 and 10 years and more than 10 years), age and sex on the results of the questionnaires was investigated. Statistical significance was defined as $P<0.05$.

\section{Results}

\section{Patient characteristics}

Eighty percent of the patients $(n=99)$ were in remission of pituitary CS. Transsphenoidal surgery was the primary therapy for $85 \%(n=84)$ of these patients (Fig. 1). Twelve percent $(n=12)$ underwent a bilateral ADX and $3 \%(n=3)$ underwent radiotherapy of the pituitary gland as primary treatment. Forty patients received one or more additional treatments because of persistent or recurrent hypercortisolism $(n=28)$ and/or because they developed Nelson's syndrome after bilateral ADX $(n=12)$. Twenty percent of all patients $(n=24)$ were in remission of adrenal CS and were previously treated by unilateral ADX.

Partial or total hypopituitarism was present in $51 \%$ of all patients $(n=63)$ and all these patients had been treated for pituitary CS. Hormonal deficiencies due to any cause, including primary adrenal insufficiency after bilateral ADX and primary hypothyroidism, were present in $65 \%$ of all patients $(n=81)$ of whom four had been treated for adrenal CS.

In contrast to all other hormonal deficiencies, presence of GH deficiency had only been investigated in $74 \%(n=73)$ of the patients that were in remission of pituitary CS (ITT or GHRH-arginine test). GH deficiency was present in $58 \%(n=42)$ of these patients. However, 21 of these 42 patients were not receiving treatment with $\mathrm{GH}$ at the time of the study despite the proven $\mathrm{GH}$ deficiency for various reasons (the initiation of treatment was pending at the time of the study, the treatment was discontinued or refused by the patients, there was a (relative) contraindication for GH substitution therapy or the deficiency was not severe enough for treatment to be covered by the health insurance companies). Four of these patients did not have other hormonal deficiencies. Furthermore, 11 of the 26 patients in whom GH deficiency had not been investigated did not have other hormonal deficiencies. For our analyses, we classified these patients as patients without hormonal deficiencies.

At the time they participated in the study, 63\% of all patients $(n=77)$ received replacement therapy with at least one hormone (replacement of cortisol in 55 patients $(45 \%)$, thyroid hormone in 49 patients $(40 \%$, of whom nine patients had primary hypothyroidism), $\mathrm{GH}$ in 21 patients (17\%), testosterone in 11 of the 17 males (68\% of all males), oestrogen in five females ( $5 \%$ of all females), desmopressin in six patients

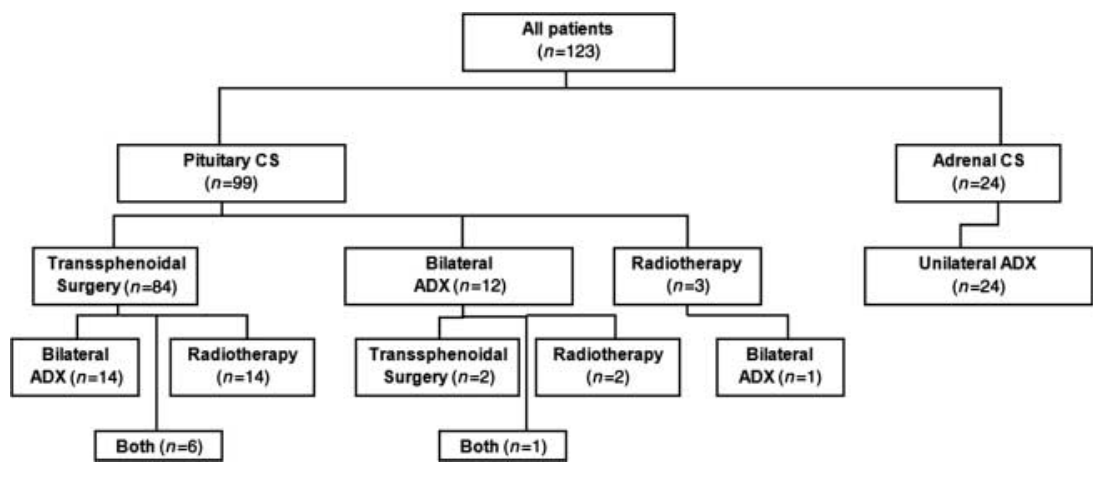

Figure 1 Overview of the treatments that the 123 patients in remission of Cushing's syndrome who participated in the quality of life study received. 
(6\%) and fludrocortisone in the 33 patients that had been treated by bilateral ADX). Substitution therapy was individually titrated to achieve at least the lower limit of our institutional reference values if a hormonal deficiency was present (except for GH therapy in the 21 patients with $\mathrm{GH}$ deficiency described earlier).

\section{Comparison of QOL between the total patient group and the healthy control group}

Each questionnaire showed that QOL in the total patient group was significantly reduced compared with the healthy control group (Fig. 2). The only items that were not significantly different between the patient and control groups were 'health change' and 'emotional role limitation' of the RAND-36. Furthermore, compared with the control subjects, significantly fewer patients had a relationship, their education level was lower, they had less paid work and more patients were unable to work (Table 1). Compared with the control subjects, significantly more patients reported co-morbidity and the average number of co-morbidities was significantly higher (Table 1). However, the prevalence of different diseases (e.g. hypertension, cardiovascular disease and diabetes) in the patient and control groups did not significantly differ, nor did smoking habits.

\section{Comparison of QOL between different patient subgroups:}

Adrenal CS $(\mathbf{n}=\mathbf{2 4})$ vs pituitary CS $(\mathbf{n}=99)$ QOL did not significantly differ between these groups on any item of any questionnaire (Fig. 2). Both patients with adrenal CS and pituitary CS scored significantly worse on all items compared with the control group with the exception of the items 'health change' and 'emotional role limitation' of the RAND-36.

Pituitary CS with hormonal deficiencies $(\mathrm{n}=77)$ vs pituitary CS without hormonal deficiencies $(\mathbf{n}=\mathbf{2 2})$ Patients treated for pituitary CS without permanent hormonal deficiencies scored significantly better than patients with hormonal deficiencies on the items fatigue and motivation of the CIS questionnaire, the CushingQOL questionnaire and the item energy of the NHP questionnaire. Furthermore, although the patients in remission of pituitary CS without hormonal deficiencies do have a significantly impaired QOL compared with the control group on $\sim 50 \%$ of the items of QOL questionnaires (physical functioning; role limitations because of physical health problems, vitality and general health perceptions of the RAND-36; depression of the HADS; experience of fatigue and concentration of the CIS; the CushingQOL questionnaire and emotional reaction and physical ability of the NHP), differences were not significant on the other items.

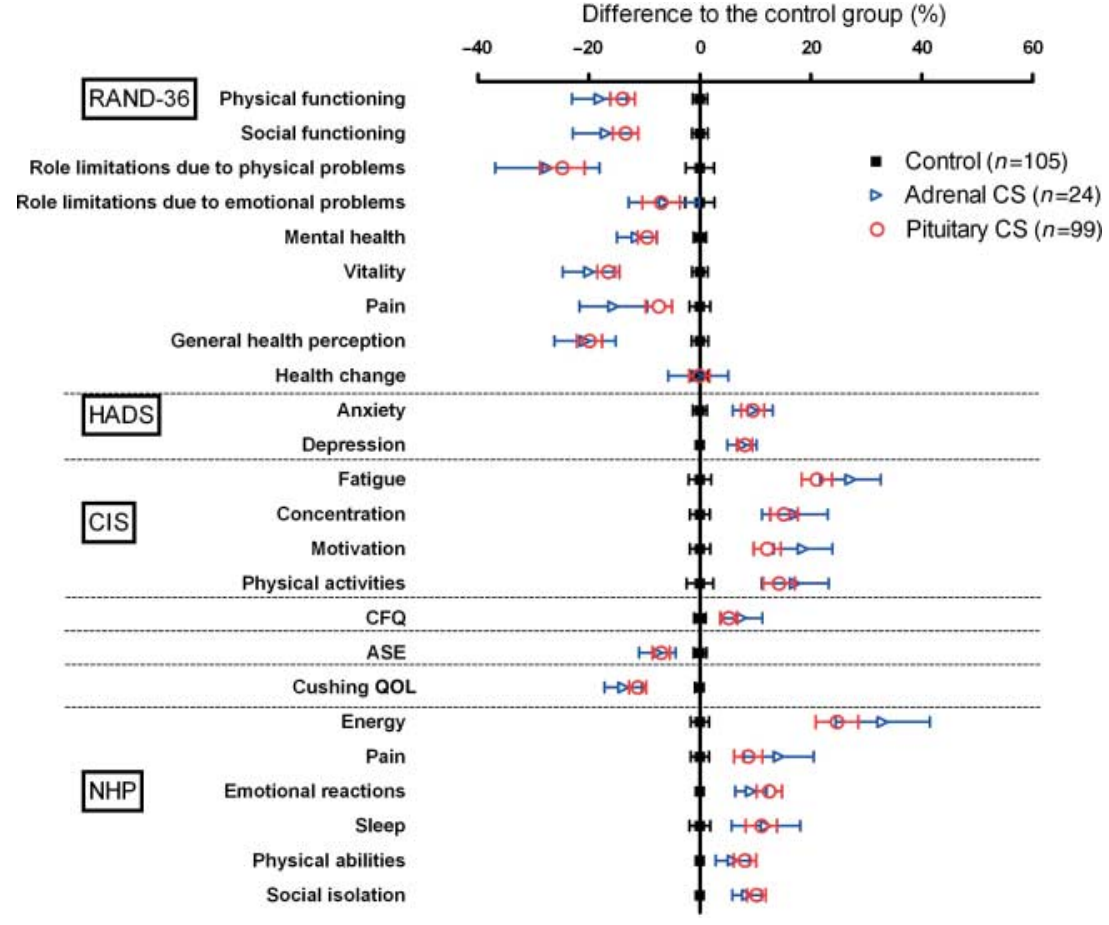

Figure 2 The difference in mean score on each dimension of the quality of life questionnaires between patients in remission of pituitary and adrenal Cushing's syndrome compared with the control group, with the S.E.M. The maximum score has been recalculated to be 100 for all questionnaires. 
Pituitary CS treated with bilateral ADX $(\mathrm{n}=33)$ vs no bilateral ADX $(n=66)$ and pituitary CS with hormonal deficiencies with glucocorticoid substitution $(\mathbf{n}=\mathbf{5 8})$ vs without glucocorticoid substitution $(\mathbf{n}=19)$ QOL did not differ between these groups on all items of all questionnaires.

Influence of duration of remission, age and gender on QOL: Multiple regression analysis showed that in the patient group, duration of remission (analysed as remission for 2-5 years, 5-10 years or 10 years and longer) significantly affected QOL, with a lower QOL if duration of remission was shorter, on the dimension 'depression' of the HADS, the dimension 'concentration' of the CIS, on the CFQ and on the CushingQOL questionnaire. Furthermore, as could be expected, duration of remission significantly affected the dimension 'health change' of the RAND-36, with more improvement in health in the past year, if duration of remission was shorter. Older age negatively influenced QOL only on the dimension 'depression' of the HADS questionnaire. Female gender negatively influenced QOL on the dimensions 'physical functioning', 'mental health', 'vitality', 'pain' and 'general health perception' of the RAND-36; the dimension 'fatigue' of the CIS questionnaire; the CFQ, ASE and Cushing QOL questionnaire; and the dimension 'energy', 'pain', 'sleep' and 'social isolation' of the NHP.

In the control group, older age had a much stronger negative influence on the reported QOL significantly affecting QOL on most items. On the other hand, female gender only significantly affected QOL in the CushingQOL questionnaire and the dimension "mental health' of the RAND-36.

\section{Discussion}

In this study, we evaluated QOL in 123 patients in longterm remission of $\mathrm{CS}$, to get more insight into the determinants related to impaired QOL. The results of this study show that, compared with a gender- and agematched control group, QOL remains impaired in all subgroups of patients in long-term remission of CS regardless of the aetiology of CS, presence of hormonal deficiencies and the treatment received. Importantly, QOL was impaired to the same extent in patients treated for adrenal CS and in patients treated for pituitary CS. Furthermore, duration of remission only affected QOL on a number of dimensions, with a better QOL if duration of remission was longer. Women in remission of CS scored worse than men on $\sim 60 \%$ of items of QOL questionnaires, while gender was of no significant influence on QOL in the control group. Age, however, did not have a strong influence on QOL in the patient group while it did have a strong influence in the control group.

Although a few previous studies on QOL in patients in remission of CS have included patients that were in remission of adrenal CS, up till now there were no studies that had specifically made a comparison between QOL in patients in long-term remission of pituitary CS and in long-term remission of adrenal CS (5, 7, 10, 13, 26). Lindholm et al. (7) made a short comment that QOL seemed quite satisfactory in the patients treated for an adrenal adenoma. However, QOL was not the main outcome of their study and data about the clinical characteristics of their patients are sparse. Furthermore, they defined relative health impairment as a score below the 25 th percentile of the Danish norm. No direct comparison was made with an age- and sexmatched control group. Webb et al. (26) compared 18 patients with adrenal and 107 patients with pituitary CS and did not find a difference in QOL between the two groups, assessed by two questionnaires (SF-36 and CushingQOL). However, a substantial part of their patients $(31 \%)$ were hypercortisolemic at the moment of investigation or had only recently been treated. Interestingly, we found that after long-term remission, QOL is at least as impaired in patients in remission of adrenal CS as in patients in remission of pituitary CS. To our knowledge, this is the first study to show this, which is surprising as we hypothesized that patients in remission of adrenal CS would have a better QOL than patients in remission of pituitary CS because they are expected not to have any hormonal deficiencies and normal endocrine physiology is restored.

The presence of hormonal deficiencies in patients treated for CS has previously been associated with impaired QOL. van Aken et al. (9) previously found that hypopituitarism was the main independent predictor of impaired QOL in patients in remission of pituitary CS. We confirmed this finding in our study and found that not only hypopituitarism but also hormonal deficiencies caused by bilateral ADX were associated with worse QOL. Our patients in remission of pituitary CS without hormonal deficiencies did have a significantly better QOL than patients with hormonal deficiencies on a number of QOL items, and they were the only patient group that did not have significantly worse QOL than the control group on $\sim 50 \%$ of QOL dimensions, but QOL remained impaired in the other $50 \%$ of dimensions.

Current glucocorticoid replacement regimens are not physiological and there is a risk of overreplacement. QOL has found to be impaired in patients receiving glucocorticoid substitution (29). Therefore, we hypothesized that glucocorticoid substitution might be an important cause of impaired QOL in patients with hormonal deficiencies. To investigate this hypothesis, we first compared the QOL of patients receiving glucocorticoid substitution with the QOL of patients with hormonal deficiencies but without glucocorticoid substitution and secondly the QOL of patients that had been treated with bilateral ADX to the QOL of patients with hormonal deficiencies that had not been treated with bilateral ADX. Because there was no difference in QOL between these patient groups, it is unlikely that the 
impaired QOL in patients in long-term remission of CS with hormonal deficiencies is strongly influenced by the glucocorticoid replacement regime.

Because QOL is impaired in all patient groups in longterm remission of CS, the cause of impaired QOL could be the previous period of long-standing exposure to high cortisol levels. There is accumulating evidence that long-standing hypercortisolism has irreversible effects on cardiovascular risk and that patients in remission of CS have persistent centripetal obesity that may lead to a state of low-grade inflammation $(2,3,30,31)$. Furthermore, CS is associated with morphological changes of the brain (including brain atrophy, reduction in total and cortical grey matter and reduced hippocampal volume), which at least partially persist after long-term remission $(32,33)$. This may explain the chronic cognitive impairments described in patients in long-term remission of CS $(4,34)$, which may negatively influence QOL. Other explanations for the impaired QOL could be the previous experience of suffering a severe illness, ineffective coping strategies or illness perceptions $(35,36)$. Future research will have to determine the exact causes of impaired QOL in patients in long-term remission of CS.

Multiple linear regression analysis showed that in our patient group, female gender negatively influenced QOL. This effect was not present in the control group. Although previous studies have also described that female gender negatively influences QOL in patients in remission of CS, it is still unclear what causes this phenomenon $(9,26)$. A possible explanation of the negative influence of female gender on QOL could be differences in the long-term effects of the previous period of hypercortisolism in men and women. This could be caused by a different clinical presentation, which has previously been described in pituitary CS (37). Another explanation could be differences in coping strategies and illness perceptions between men and women. Although gender differences in coping strategies and illness perceptions have been reported in numerous other diseases $(38,39)$, this has not yet been investigated in patients with CS.

Although shorter duration of remission did have a negative impact on QOL on a number of dimensions, QOL was not affected by duration of remission on most dimensions of QOL, suggesting that the majority of effects of CS on QOL have reached a stable situation after 2 years of remission. van Aken et al. (9) even found that duration of remission did not affect QOL at all. However, in contrast to van Aken, who analysed duration of remission as a continuum, we analysed duration of remission in different categories (from 2 to 5 years, 5 to 10 years and $>10$ years) because we hypothesized that the largest effect of remission on QOL would take place in the first decade after treatment. Interestingly, in our study, the (dimensions of the) QOL questionnaires that were affected by duration of remission with a lower QOL, if duration of remission was shorter, were the dimensions 'depression' of the HADS, 'concentration' of the CIS, the CFQ and on the CushingQOL questionnaire. The combination of these QOL dimensions suggests problems in coping with the recent experience of CS, which improves as time goes by. Another possible explanation could be that the effect of hypercortisolism on the brain, causing psychological problems and cognitive impairments, takes longer to reach a stable situation after remission than other effects of hypercortisolism.

Strengths of this study are the relatively large number of patients included and the long average duration of remission $(13.3 \pm 10.4$ years). A limitation of this study is the fact that GH deficiency was not ruled out in 26 patients in remission of pituitary CS. Because 11 of these patients had no other hormonal deficiencies and normal IGF1 values, we analysed these patients as having no hormonal deficiencies. If some of these patients do have GH deficiency, this may have negatively influenced QOL in the patient group without hormonal deficiencies. Furthermore, 21 patients with proven GH deficiency were not receiving treatment for a number of different reasons. This could have negatively influenced the QOL of the total patient group and the patient group with hormonal deficiencies. However, in patients with adult-onset GH deficiency, GH therapy has only been found to have a positive effect on QOL if disease-specific questionnaires are used. In studies that use generic QOL questionnaires, as we used in this study, the positive effect of GH therapy on QOL in GH-deficient patients is much more controversial and most studies that did find a positive effect of QOL only found this in a few dimensions of the generic QOL questionnaires (40). Therefore, the presence of untreated GH deficiency can certainly not account for the obvious impairment of QOL of the total patient group. Another possible limitation of this study is that not all patients found a control subject and not all control subjects were gender matched. However, we controlled for gender in our analysis using a multiple regression analysis. Furthermore, not all control subjects were healthy, reporting co-morbidity in $57 \%$ (Table 1). However, if this influenced QOL in the control group, it would have been a negative influence on QOL, reducing the difference in QOL between the patient and control groups.

In conclusion, QOL remains impaired in patients in long-term remission of CS regardless of aetiology, presence of hormonal deficiencies and treatment strategies. The cause of impaired QOL remains unclear and is probably multifactorial. More research is needed to establish the causes of impaired QOL, and hopefully, this will provide targets for interventions that can improve QOL in patients in long-term remission of CS in the future.

\section{Declaration of interest}

The authors declare that there is no conflict of interest that could be perceived as prejudicing the impartiality of the research reported. 


\section{Funding}

This work was supported by the Dutch Addison and Cushing Society (NVACP), currently known as The Dutch Adrenal Society (NVACP), and the Friends of NVACP Foundation, soon to be changed to Dutch Adrenal Fund, whom we owe many thanks.

\section{References}

1 Newell-Price J, Bertagna X, Grossman AB \& Nieman LK. Cushing's syndrome. Lancet 2006367 1605-1617. (doi:10.1016/S01406736(06)68699-6)

2 Barahona MJ, Sucunza N, Resmini E, Fernandez-Real JM, Ricart W, Moreno-Navarrete JM, Puig T, Farrerons J \& Webb SM. Persistent body fat mass and inflammatory marker increases after long-term cure of Cushing's syndrome. Journal of Clinical Endocrinology and Metabolism 200994 3365-3371. (doi:10.1210/jc.2009-0766)

3 Colao A, Pivonello R, Spiezia S, Faggiano A, Ferone D, Filippella M, Marzullo P, Cerbone G, Siciliani M \& Lombardi G. Persistence of increased cardiovascular risk in patients with Cushing's disease after five years of successful cure. Journal of Clinical Endocrinology and Metabolism 199984 2664-2672. (doi:10. $1210 /$ jc.84.8.2664)

4 Tiemensma J, Kokshoorn NE, Biermasz NR, Keijser BJ, Wassenaar MJ, Middelkoop HA, Pereira AM \& Romijn JA. Subtle cognitive impairments in patients with long-term cure of Cushing's disease. Journal of Clinical Endocrinology and Metabolism 201095 2699-2714. (doi:10.1210/jc.2009-2032)

5 Pikkarainen L, Sane T \& Reunanen A. The survival and well-being of patients treated for Cushing's syndrome. Journal of Internal Medicine 1999245 463-468. (doi:10.1046/j.1365-2796.1999. 00483.x)

6 Nagesser SK, van Seters AP, Kievit J, Hermans J, Krans HM \& van de Velde CJ. Long-term results of total adrenalectomy for Cushing's disease. World Journal of Surgery $2000 \mathbf{2 4} 108-113$. (doi:10.1007/s002689910020)

7 Lindholm J, Juul S, Jorgensen JO, Astrup J, Bjerre P, Feldt-Rasmussen U, Hagen C, Jorgensen J, Kosteljanetz M, Kristensen L, Laurberg P, Schmidt K \& Weeke J. Incidence and late prognosis of Cushing's syndrome: a population-based study. Journal of Clinical Endocrinology and Metabolism 200186 117-123. (doi:10.1210/jc.86.1.117)

8 Hawn MT, Cook D, Deveney C \& Sheppard BC. Quality of life after laparoscopic bilateral adrenalectomy for Cushing's disease. Surgery 2002132 1064-1068. (doi:10.1067/msy.2002.128482)

9 van Aken MO, Pereira AM, Biermasz NR, van Thiel SW, Hoftijzer HC, Smit JW, Roelfsema F, Lamberts SW \& Romijn JA. Quality of life in patients after long-term biochemical cure of Cushing's disease. Journal of Clinical Endocrinology and Metabolism 200590 3279-3286. (doi:10.1210/jc.2004-1375)

10 Sonino N, Bonnini S, Fallo F, Boscaro M \& Fava GA. Personality characteristics and quality of life in patients treated for Cushing's syndrome. Clinical Endocrinology 200664 314-318. (doi:10.1111/j.1365-2265.2006.02462.x)

11 Thompson SK, Hayman AV, Ludlam WH, Deveney CW, Loriaux DL \& Sheppard BC. Improved quality of life after bilateral laparoscopic adrenalectomy for Cushing's disease: a 10-year experience. Annals of Surgery 2007245 790-794. (doi:10. 1097/01.sla.0000251578.03883.2f)

12 van der Klaauw AA, Kars M, Biermasz NR, Roelfsema F, Dekkers OM, Corssmit EP, van Aken MO, Havekes B, Pereira AM, Pijl H, Smit JW \& Romijn JA. Disease-specific impairments in quality of life during long-term follow-up of patients with different pituitary adenomas. Clinical Endocrinology 200869 775-784. (doi:10.1111/j.1365-2265.2008.03288.x)

13 Lindsay JR, Nansel T, Baid S, Gumowski J \& Nieman LK. Long-term impaired quality of life in Cushing's syndrome despite initial improvement after surgical remission. Journal of Clinical Endocrinology and Metabolism 200691 447-453. (doi:10.1210/jc. 2005-1058)

14 Heald AH, Ghosh S, Bray S, Gibson C, Anderson SG, Buckler H \& Fowler HL. Long-term negative impact on quality of life in patients with successfully treated Cushing's disease. Clinical Endocrinology 200461 458-465. (doi:10.1111/j.1365-2265.2004.02118.x)

15 Biller BMK, Grossman AB, Stewart PM, Melmed S, Bertagna X, Bertherat J, Buchfelder M, Colao A, Hermus AR, Hofland LJ, Klibanski A, Lacroix A, Lindsay JR, Newell-Price J, Nieman LK, Petersenn S, Sonino N, Stalla GK, Swearingen B, Vance ML, Wass JAH \& Boscaro M. Treatment of ACTH-dependent Cushing's syndrome: a consensus statement. Journal of Clinical Endocrinology and Metabolism 200893 2454-2462. (doi:10. $1210 /$ jc. 2007-2734)

16 Molitch ME, Clemmons DR, Malozowski S, Merriam GR, Shalet SM, Vance ML \& Stephens PA. Evaluation and treatment of adult growth hormone deficiency: an Endocrine Society Clinical Practice Guideline. Journal of Clinical Endocrinology and Metabolism 200691 1621-1634. (doi:10.1210/jc.2005-2227)

17 Arlt W \& Allolio B. Adrenal insufficiency. Lancet $2003 \mathbf{3 6 1}$ 1881-1893. (doi:10.1016/S0140-6736(03)13492-7)

18 Van der Zee KI, Sanderman R, Heyink JW \& de Haes H. Psychometric qualities of the RAND 36-Item Health Survey 1.0: a multidimensional measure of general health status. International Journal of Behavioral Medicine 19963 104-122. (doi:10.1207/ s15327558ijbm0302_2)

19 van der Zee KI \& Sanderman R. Het meten van de algemene gezondheidstoestand met de RAND-36. Een Handleiding 1992. Groningen: Rijksuniversiteit Groningen, Noordelijk Centrum voor Gezondheidsvraagstukken. ISBN 90-72156-60-9.

20 Zigmond AS \& Snaith RP. The hospital anxiety and depression scale. Acta Psychiatrica Scandinavica $1983 \quad 67$ 361-370. (doi:10.1111/j.1600-0447.1983.tb09716.x)

21 Spinhoven P, Ormel J, Sloekers PP, Kempen GI, Speckens AE \& Van Hemert AM. A validation study of the Hospital Anxiety and Depression Scale (HADS) in different groups of Dutch subjects. Psychological Medicine $1997 \quad 27$ 363-370. (doi:10.1017/ S0033291796004382)

22 Beurskens AJ, Bultmann U, Kant I, Vercoulen JH, Bleijenberg G \& Swaen GM. Fatigue among working people: validity of a questionnaire measure. Occupational and Environmental Medicine 200057 353-357. (doi:10.1136/oem. 57.5.353)

23 Broadbent DE, Cooper PF, FitzGerald P \& Parkes KR. The Cognitive Failures Questionnaire (CFQ) and its correlates. British Journal of Clinical Psychology 198221 1-16. (doi:10.1111/j.2044-8260. 1982.tb01421.x)

24 Heatherton TF \& Polivy J. Development and validation of a scale for measuring state self-esteem. Journal of Personality and Social Psychology 199160 895-910. (doi:10.1037/0022-3514. 60.6.895)

25 van Lankveld WG, Vonk MC, Teunissen H \& van den Hoogen FH. Appearance self-esteem in systemic sclerosis - subjective experience of skin deformity and its relationship with physician-assessed skin involvement, disease status and psychological variables. Rheumatology 200746 872-876. (doi:10.1093/rheumatology/ kem008)

26 Webb SM, Badia X, Barahona MJ, Colao A, Strasburger CJ Tabarin A, van Aken MO, Pivonello R, Stalla G, Lamberts SW \& Glusman JE. Evaluation of health-related quality of life in patients with Cushing's syndrome with a new questionnaire. European Journal of Endocrinology 2008158 623-630. (doi:10.1530/EJE07-0762)

27 Hunt SM, McKenna SP, McEwen J, Williams J \& Papp E. The Nottingham Health Profile: subjective health status and medical consultations. Social Science \& Medicine 198115 221-229.

28 Erdman RA, Passchier J, Kooijman M \& Stronks DL. The Dutch version of the Nottingham Health Profile: investigations of psychometric aspects. Psychological Reports $1993 \quad \mathbf{7 2}$ 1027-1035. (doi:10.2466/pr0.1993.72.3.1027) 
29 Hahner S, Loeffler M, Fassnacht M, Weismann D, Koschker AC, Quinkler M, Decker O, Arlt W \& Allolio B. Impaired subjective health status in 256 patients with adrenal insufficiency on standard therapy based on cross-sectional analysis. Journal of Clinical Endocrinology and Metabolism $2007923912-3922$. (doi:10.1210/jc.2007-0685)

30 Prazny M, Jezkova J, Horova E, Lazarova V, Hana V, Kvasnicka J, Pecen L, Marek J, Skrha J \& Krsek M. Impaired microvascular reactivity and endothelial function in patients with Cushing's syndrome: influence of arterial hypertension. Physiological Research 200857 13-22.

31 Faggiano A, Pivonello R, Spiezia S, De Martino MC, Filippella M, Di Somma C, Lombardi G \& Colao A. Cardiovascular risk factors and common carotid artery caliber and stiffness in patients with Cushing's disease during active disease and 1 year after disease remission. Journal of Clinical Endocrinology and Metabolism 2003 88 2527-2533. (doi:10.1210/jc.2002-021558)

32 Bourdeau I, Bard C, Noel B, Leclerc I, Cordeau MP, Belair M, Lesage J, Lafontaine L \& Lacroix A. Loss of brain volume in endogenous Cushing's syndrome and its reversibility after correction of hypercortisolism. Journal of Clinical Endocrinology and Metabolism 200287 1949-1954. (doi:10.1210/jc.87.5. 1949)

33 Resmini E, Santos A, Gomez-Anson B, Vives Y, Pires P, Crespo I, Portella MJ, de Juan-Delago M, Barahona MJ \& Webb SM. Verbal and visual memory performance and hippocampal volumes, measured by 3-Tesla magnetic resonance imaging, in patients with Cushing's syndrome. Journal of Clinical Endocrinology and Metabolism 2012 97 663-671. (doi:10.1210/jc.2011-2231)

34 Forget H, Lacroix A \& Cohen H. Persistent cognitive impairment following surgical treatment of Cushing's syndrome. Psychoneuroendocrinology 200227 367-383. (doi:10.1016/S0306-4530(01) 00059-2)

35 Tiemensma J, Kaptein AA, Pereira AM, Smit JW, Romijn JA \& Biermasz NR. Coping strategies in patients after treatment for functioning or nonfunctioning pituitary adenomas. Journal of Clinical Endocrinology and Metabolism 201196 964-971. (doi:10.1210/jc.2010-2490)

36 Tiemensma J, Kaptein AA, Pereira AM, Smit JW, Romijn JA \& Biermasz NR. Negative illness perceptions are associated with impaired quality of life in patients after long-term remission of Cushing's syndrome. European Journal of Endocrinology 2011165 527-535. (doi:10.1530/EJE-11-0307)

37 Pecori Giraldi F, Moro M \& Cavagnini F. Gender-related differences in the presentation and course of Cushing's disease. Journal of Clinical Endocrinology and Metabolism $2003 \mathbf{8 8} 1554-1558$. (doi:10.1210/jc.2002-021518)

38 Carstensen TB, Frostholm L, Oernboel E, Kongsted A, Kasch H, Jensen TS \& Fink P. Are there gender differences in coping with neck pain following acute whiplash trauma? A 12-month followup study European Journal of Pain 201216 49-60. (doi:10.1016/j. ejpain.2011.06.002)

39 Ninot G, Fortes M, Poulain M, Brun A, Desplan J, Prefaut C \& Varray A. Gender difference in coping strategies among patients enrolled in an inpatient rehabilitation program. Heart Lung 2006 35 130-136. (doi:10.1016/j.hrtlng.2005.09.004)

40 Hazem A, Elamin MB, Bancos I, Malaga G, Prutsky G, Domecq JP, Elraiyah TA, bu Elnour NO, Prevost Y, Almandoz JP, ZeballosPalacios C, Velasquez ER, Erwin PJ, Natt N, Montori VM \& Murad MH. Body composition and quality of life in adults treated with GH therapy: a systematic review and meta-analysis. European Journal of Endocrinology 2012166 13-20. (doi:10.1530/ EJE-11-0558)

Received 10 April 2012

Revised version received 21 August 2012

Accepted 30 August 2012 